\title{
Teammate Influence on Collegiate Swimmers' Basic Psychological Need Satisfaction: A Qualitative Perspective
}

\author{
Johannes Raabe \\ University of Tennessee \\ Rebecca A. Zakrajsek \\ University of Tennessee \\ Tucker Readdy \\ University of Wyoming
}

\begin{abstract}
To enhance student-athletes' psychological welfare and motivation it is essential to foster positive relationships and interactions with those in their surroundings, especially when considering that others' actions toward them can have a significant impact on their thoughts, feelings, and behaviors (Vallerand \& Losier, 1999). Deci and Ryan's (2000) self-determination theory offers an ideal lens to understand social influences as it suggests that various social factors have a direct influence on individuals' basic psychological need satisfaction (Vallerand, 1997), which in turn affects the development of self-determined forms of motivation and wellbeing (Deci \& Ryan, 2000). The purpose of the current research was to explore how teammates act as social factors for National Collegiate Athletic Association (NCAA) Division I swimmers' basic psychological need fulfillment. Eight NCAA Division I swimmers participated in semistructured interviews. Consensual qualitative research (Hill, Thompson, \& Williams, 1997) procedures revealed three domains: (a) foundational components of a need-fulfilling team environment, (b) elements in practice that nurtured athletes' perceptions of competence, and (c) teammate interactions outside the pool which impacted athletes' perceptions of relatedness. Results showed that positive teammate interactions allowed athletes to create a team environment that fostered basic psychological need satisfaction and helped members to internalize their team's values, goals, and behaviors.
\end{abstract}

Keywords: self-determination theory, NCAA, teammate interactions, elite sport, qualitative research

Raabe and Zakrajsek are with the Dept. of Kinesiology, Recreation, and Sport Studies, University of Tennessee, Knoxville, TN. Readdy is with the Dept. of Kinesiology and Health, University of Wyoming, Laramie, WY. Address author correspondence to Johannes Raabe at jraabe@vols.utk.edu. 
Collegiate student-athletes face multiple demands in their pursuit of excellence (Vallerand \& Losier, 1999). Not only do these student-athletes face the challenges of nonathletes (e.g., academic standards, social adjustment, career exploration, intellectual growth), but they are also asked to practice and perform at an elite level in their sport (Watt \& Moore, 2001). Therefore, student-athletes frequently have to wake up before 6am for practice, attend study halls late at night to prepare for class, or engage in other not inherently enjoyable behaviors to meet the athletic and academic demands. In addition, elite sport often focuses on results, which can create an overtly competitive and stressful environment (Frøyen \& Pensgaard, 2014).

One approach to enhancing student-athletes' motivation and psychological welfare is to foster positive relationships and interactions with meaningful people in their surroundings, especially when considering that others' actions toward them can have a significant impact on their thoughts, feelings, and behaviors (Vallerand $\&$ Losier, 1999). Considering the variety of social interactions that can take place within the sport environment, Mageau and Vallerand (2003) argued that the coachathlete relationship is one of the most influential factors because athletes often view coaches as mentors and parental figures (Gould, Dieffenbach, \& Moffett, 2002). While coaches can arguably be considered the main directors within the athletic context and are highly influential, collegiate athletes compete as part of a team and therefore typically spend a significant amount of time around their peers in practice, competition, travel, and free time. Furthermore, researchers have revealed the importance of group influence as it represents a fundamental antecedent to performance (Carron, Colman, Wheeler, \& Stevens, 2002), interpersonal development (Hanson, Larson, \& Dworkin, 2003), coping (Pierce, Sarason, \& Sarason, 1996), social functioning, motivation, and well-being (Mack et al., 2011). Accordingly, the social environment, and in particular teammate interactions, can play a key role in determining important outcomes related to athletes' sport participation (Evans, Eys, \& Wolf, 2013). Thus, the purpose of the current research was to explore how teammates act as social factors for National Collegiate Athletic Association (NCAA) Division I (DI) swimmers' basic psychological need fulfillment.

Deci and Ryan's (2000) self-determination theory offers an ideal lens to understand how social factors such as teammates influence athletes' motivation and wellbeing. This theory was chosen because it considers not only the quantity, but also the quality of motivation. Therefore, rather than assuming that more motivation is simply better, self-determination theory offers insight into potentially diverse influences of categorically different types of motivation on behavior (Teixeira, Carraca, Markland, Silva, \& Ryan, 2012). In addition, Deci and Ryan (2000) propose that "humans are active, growth-oriented organisms who are naturally inclined toward integration of their psychic elements into a unified sense of self and integration of themselves into larger social structures" (p. 229), which aligns with the current study's focus on social interactions. The framework suggests that various social factors have a direct influence on individuals' perception and satisfaction of their inherent basic psychological needs (see Vallerand, 1997) of competence (the need to interact effectively with the environment), autonomy (the need to be the director of one's actions that are in accordance with one's values), and relatedness (the need to be valued and accepted; Deci \& Ryan, 2000). If individuals feel competent, they have a sense of being able to perform at a level that is appropriate for the setting. Autonomy is fulfilled when there is a certain amount of choice and input in decisions 
that are valued rather than them being dictated solely by others. Relatedness refers to a sense of being an acknowledged and meaningful member of the group and feeling comfortable in one's role (Deci \& Ryan, 2000).

Within a given setting (e.g., sport) the satisfaction of these three basic psychological needs contributes to an individuals' degree of internalization, which is "an active, natural process in which individuals attempt to transform socially sanctioned mores or requests into personally endorsed values and self-regulations" (Deci \& Ryan, 2000, pp. 235-236). In the context of collegiate athletics this process of internalization can have a meaningful influence on team functioning as well as individual athletes' motivation and well-being. First, it determines how well athletes are able to adapt to their team's values, goals, and behaviors, which in turn contributes to the group's harmony and stability (Deci \& Ryan, 2000). Second, based on the degree of internalization, athletes can individually demonstrate different types of motivation or behavioral regulation (Deci \& Ryan, 2000).

Among these behavioral regulations, external and introjected regulations are characterized as non-self-determined because a person's actions are determined by sources completely or partially external to the individual. External regulation is the classic process of being controlled by external contingencies. Someone who is motivated by such regulators engages in an activity solely for tangible rewards or to avoid negative consequences. Introjected motivation is still a controlled motivation where behaviors are completed to experience positive or prevent negative internalized feelings such as pride, guilt, and/or shame. In contrast, identified and integrated regulations are considered to be self-determined because the individual participates in behaviors with a sense of free will. When people identify the value of a certain behavior and the positive effect it can have on other aspects of their life, they are demonstrating identified behavioral regulation. Hence, engagement in an activity is based on helping with another, related goal. Integrated regulation is present when individuals have fully accepted the behavior's worth and recognize it as part of their values and identity (Deci \& Ryan, 2000). Thus, the process of internalization suggests that the regulation governing an individual's participation in a specific action can shift over time as the person progressively endorses the importance of behaviors deemed valuable to the social functioning of the larger group that person participates in. For example, waking up before 6am for practice or attending study hall might not be inherently self-determined but through the process of internalization athletes can learn to the see the value of such behaviors and thus engage in them with an enhanced sense of volition.

Self-determined motivation developed through the process of internalization can have many positive cognitive, affective, and behavioral consequences (Deci \& Ryan, 2000). For example, athletes who were self-determined gave more effort, experienced lower levels of performance-related anxiety, and had higher levels of well-being in and out of sport compared with athletes who did not demonstrate self-determined motivation (Mack et al., 2011; Vallerand, 1997; Vallerand \& Losier, 1999). Furthermore, Podlog and Dionigi (2010) revealed that self-determined motivation was related to persistence when faced with adversity (e.g., injury) and enhanced psychological states in the rehabilitation process (e.g., decreased perceptions of threat, unfairness, and ego damage). While these outcomes are meaningful in their own right, it is also valuable to note that a positive relationship has been found between self-determined motivation and success in competition (Gillet, Berjot, \& Gobance, 2009). 
Although researchers using self-determination theory (Deci \& Ryan, 2000) as a framework have primarily focused on coach-athlete relationships and basic psychological need satisfaction (e.g., Hollembeak \& Amorose, 2005; Podlog \& Dionigi, 2010), attention has recently been directed to understanding the role of teammate relationships and need fulfillment (e.g., Joesaar, Hein, \& Hagger, 2011; Kipp \& Weiss, 2013). Kipp and Weiss (2013) surveyed 303 gymnasts between ten and 17 years of age to explore determinants of basic psychological need satisfaction. In regards to peer influences, results demonstrated that the quality of friendship with athletes' best friend on the team predicted their fulfillment of relatedness and competence. Specifically, having such a positive relationship was strongly associated with a greater sense of belonging and low to moderately connected to a greater perception of ability. However, Kipp and Weiss (2013) only measured friendship quality with one particular friend. In contrast, Joesaar and colleagues (2011) surveyed nonelite youth athletes from a variety of team sports (e.g., basketball, soccer, volleyball) to assess the relationship between the motivational climate created by peers, need fulfillment, and motivation. The findings showed that participants who perceived their teammates to foster a positive motivational climate (i.e., emphasizing learning processes, improvement, and effort) reported greater levels of competence, autonomy, and relatedness compared with those who perceived the motivational climate to focus on competition, winning, and social comparison. These findings are compelling, yet the number of studies exploring peers' influences on need fulfillment is limited and therefore further research is necessary to more comprehensively explore this relationship.

Previous self-determination literature focusing on peer influences has primarily been conducted with physical education (Cox, Duncheon, \& McDavid, 2009), noncompetitive club (Joesaar et al., 2011), or youth sport populations (Kipp \& Weiss, 2013). As an exception, DeFreese and Smith (2013) explored the effect of teammate support on collegiate athletes' motivation but they did not assess need fulfillment. Vallerand and Losier (1999) suggested that basic psychological need satisfaction can be affected by various social factors (e.g., competition/cooperation, success/failure, and coaches' behaviors toward athletes) in the respective environment. It appears reasonable to suggest that the context of NCAA DI and its associated social mores, requests, and expectations differ from the previously explored settings. Thus, an investigation of peer influences at the NCAA DI level could potentially add to the self-determination theory literature and offer practical suggestions for professionals working with collegiate athletes.

In addition, the self-determination theory literature assessing peers or teammates as social influences on basic psychological need satisfaction has been quantitative in nature. Although this information is useful, there is a need to further explore in what ways teammate interactions can enhance perceptions of competence, autonomy, and relatedness. This can likely offer practical suggestions that allow coaches to create need-fulfilling peer interactions. Consequently, the current study used a qualitative approach to gain a more in-depth understanding of the nature of teammate interactions as it allowed the researchers to "remain open to discovering relationships, concepts, and ideas about the topic they may not have considered prior to data collection" (Hill, Thompson, \& Williams, 1997, p. 518). Thus, the current research has the potential to build on previous quantitative findings by "providing much richer detail or by painting in a more complete picture that was 
only 'sketched' via the results of quantitative work" (Horn, 2011, p. 297). Such a design has previously only been applied by a limited number of researchers when examining self-determination theory variables (e.g., Podlog \& Dionigi, 2010).

In accordance with self-determination theory (Deci \& Ryan, 2000), the purpose of this qualitative study was to gain a more in-depth understanding of how teammates act as social factors for NCAA DI swimmers' basic psychological need fulfillment. More specifically, this research was designed to answer the following question: In what ways do teammates satisfy NCAA DI swimmers' basic psychological needs for competence, autonomy, and relatedness?

\section{Methods}

\section{Participants}

Participants were from a NCAA DI swim team at a university in the Southeastern part of the United States of America. A total of eight members (five females and three males) from a sample of convenience participated in the study. Seven of these individuals self-identified as White/Caucasian and one as African-American. The average age was 19.75 years $(S D=1.16)$, which included two freshmen, four sophomores, one junior, and one senior. This sample was representative of the entire team $(N=44)$, which was split almost evenly between females and males and also had an average age of 19.75 years $(S D=1.42)$. Data from eight participants were considered satisfactory to reach the point of data saturation (see Seidman, 2006). Specifically, after interviewing five participants, the first author noticed that similar themes continued to emerge without the addition of new information. After including three additional interviews and conducting initial analyses, the research team agreed that no supplementary information had been gathered. This total of eight participants is consistent with recommendations for consensual qualitative research (CQR; Hill et al., 1997).

\section{Procedures}

Upon Institutional Review Board approval by the respective university, the research study was introduced to the team $(N=44)$ by the first author before a practice at the beginning of the competitive season. A total of 15 team members were initially interested in being interviewed. However, only eight swimmers ultimately participated and gave informed consent for their involvement, as the other seven were unable to schedule an interview before the point of data saturation had been achieved.

Interviews were semistructured in nature to allow for consistency in questions asked as well as the opportunity for follow-up questions and probes (Hill et al., 1997). Questions for the interviews were developed from literature in the area of sport psychology, specifically related to self-determination theory (Deci \& Ryan, 2000). In this process the researchers used interview guides that had been used in previous studies (King, 2014; Raabe, 2013) as a foundation. The interview guide was constructed to explore the influence of teammate interactions on participants' satisfaction of the need for competence (e.g., "In what ways do your teammates influence how capable you feel in your sport?"), autonomy (e.g., "How do you think your teammates allow you to give input in team decisions?"), and relatedness 
(e.g., "Please tell me about how accepted you feel by your teammates as part of the group?"). Thus, the study primarily attempted to explore teammate interactions with varying degrees of need fulfillment which should be considered conceptually different from need thwarting (see Costa, Ntoumanis, \& Bartholomew, 2015). Two sport psychology professionals (i.e., second and third author) and one doctoral student in sport psychology (i.e., first author) deliberated these questions until consensus was reached about a guide that adequately inquired about each of the three basic psychological needs. To increase the likelihood of effectively exploring the constructs of interest, the first author conducted two pilot interviews with a sample of convenience before the beginning of data collection. Based on the pilot interviews, slight adjustments were made to add clarity (e.g., wording of questions) to two of the questions on the interview guide. Following the pilots, qualitative interviews (which lasted approximately $45 \mathrm{~min}$ ) were conducted by the first author in person, audio-recorded, and transcribed verbatim.

\section{Research Team Members and Subjectivities}

By highlighting researchers' backgrounds and subjectivities the reader has the ability to gain perspective about their potential influence on the data analysis (Hill et al., 1997). The research team in the current study consisted of four members from the same university (i.e., first two authors and two research assistants) and an external auditor from a different institution (i.e., third author). The majority of those researchers have experience with or in collegiate swimming as athletes, consultants, or researchers. The first author is a Caucasian male doctoral student in sport psychology who has provided consulting services for collegiate and high school swimmers and swim coaches; however, he has no professional relationship with the study participants. The second author is a Caucasian female $\mathrm{PhD}$ in sport psychology who was a swimmer at the collegiate level and is familiar with the participating team's head coach. Research assistants were one female and one male Caucasian master's students in sport psychology with no prior experience with or in collegiate swimming. The external auditor is a male Caucasian $\mathrm{PhD}$ in sport psychology who previously conducted research with a different collegiate swim team. All members of the research team had previous training in and experience with qualitative research.

Before engaging in the data analysis the researchers reflected on and discussed their personal biases. All team members had previously conducted self-determination theory research (Deci \& Ryan, 2000), which could potentially influence how they interpreted the data. Research team members also shared the belief that male and female participants may report different views about the influence of teammates on basic psychological need satisfaction. Furthermore, they expected that in the sport of swimming athletes are primarily focused on their individual performance rather than their collective team's success.

\section{Data Analysis}

Interview data were analyzed utilizing CQR methodology (Hill et al., 1997). Research team members initially discussed literature about the process of conducting CQR (Hill et al., 1997; Hill et al., 2005) and recent articles in sport psychology 
that used CQR methodology (e.g., Steinfeldt, Zakrajsek, Bodey, Middendorf, \& Martin, 2013). Several procedures were employed to establish trustworthiness of the data. First, the eight participants were provided a copy of their transcript as a form of member check, which allowed them to offer any feedback before data analysis; no modifications were suggested. Then, the researchers deliberated their personal biases and continued to monitor these assumptions throughout the analysis to ground conclusions in the data instead of personal interpretations (Hill et al., 1997). Next, the four members of the research team read the interview transcripts and independently identified preliminary themes from the participants' responses. Each research team member was instructed to read the transcripts several times across participants and questions to enhance the credibility of their individual analyses. Researchers then met multiple times to discuss their independently derived themes and develop consensus on an initial thematic structure including domains and categories, which are often referred to as themes and subthemes in other qualitative approaches (see Merriam, 2009). In this process the researchers did not attempt to generate theory but rather synthesize information in structures that "faithfully represent how participants describe their own experiences" (Hill et al., 2005, p. 197). Once the domains and categories were negotiated research team members identified illustrative core ideas. While domains and categories group data about similar topics, creating core ideas is "a process of 'editing' the participant's words into a format that is concise, clear, and comparable across cases" (Hill et al., 2005 , p. 205). Thus, core ideas are descriptive labels, which provide detail to the individual categories and integrate the data (Hill et al., 1997). The research team members presented, discussed, and negotiated their own analytic impressions of the data until consensus was reached. This analyst comparison contributed to the credibility of the process. The initial results (i.e., domains, categories, and core ideas) were then sent to the external auditor for autonomous feedback, to increase the rigor of the process, and curtail possible group process issues (e.g., power struggles) among the research team members (Hill et al., 1997). The research group reconvened after receiving the external auditor's feedback to incorporate suggestions provided and to reach consensus about the final categorizations; minor changes were made to the labeling of two domains. As a final step, a cross analysis procedure was used to validate the thematic structure. Two members of the research team (i.e., first and second author) individually coded the occurrence of the core ideas across the transcripts. They then met to consensually establish a frequency count that indicated how many transcripts (i.e., cases) a category was found in. Thus, the cross analysis helps to estimate the representativeness of each category to the sample. Every category was labeled (see Table 1) as general (i.e., all the cases), typical (i.e., more than half the cases), or variant (i.e., half the cases or less; Hill et al., 1997).

\section{Results}

The consensus building process of CQR revealed three domains and 10 categories. The domains that emerged from the data were: (a) foundational components of a need-fulfilling team environment, (b) elements in practice that nurtured athletes' perceptions of competence, and (c) teammate interactions outside the pool which 


\section{Table 1 Summary of Domains, Categories, Core Ideas, and Frequencies}

\begin{tabular}{lll}
\hline Domains/Categories Illustrative Core Idea & Frequency
\end{tabular}

Domain 1: Foundational components of a need-fulfilling team environment

a) Group- There is a sense of pride, love, and trust that is motivating; everyone

General

ness is working to help the team do well and strive toward a common purpose.

b) Individual Knowing and revisiting teammates' detailed goals and making them goals visual in the locker room helps to feel connected and hold each other accountable.

c) Valued Seniors and established leaders are the primary decision makers. roles Informal roles on the team are related to performance, encouragement, and support. Every person matters and has a role that is valuable.

d) Mutual

Allowing teammates to voice their opinion, understanding cultural acceptance differences, and being able to be oneself lead to feeling accepted by the group which increases comfort and enjoyment.

Typical

General

Typical

Domain 2: Elements in practice that nurtured athletes' perceptions of competence

a) Teammate Teammates' genuine recognition and belief in capability to reach or recognition exceed goals increases perception of ability. Their support helps to and support push through fatigue and inspires to put forth good effort and achieve goals.

b) Intrateam There is a strong culture of good competition; racing and pushing competition each other in every practice enhances ability and confidence.

c) Peer Teammates coach each other by correcting technique and highlightcoaching ing what was done well. By verbalizing feedback both teammates benefit and learn from mistakes.

General

Domain 3: Teammate interactions outsides the pool which impacted athletes' perceptions of relatedness

a) Social life Free time is almost solely spent with teammates creating a special bond which extends beyond the pool and nurtures a sense of togethTypical erness.

b) Conflicts Conflicts are primarily related to issues outside the pool such as partying, interteam dating, different interests, bickering, and breaking

General rules, which can decrease feelings of togetherness.

c) Being on

Conflicts get resolved through team meetings, talking it out, and

the same reminding each other of the team's purpose, allowing the group to page move in a common direction.

Note . General $=$ all the cases; Typical $=$ more than half the cases; Variant $=$ half the cases or less. 
impacted athletes' perceptions of relatedness. The cross analysis procedure validated the domains and indicated the frequency of the categories (see Table 1). All names used for the quotes provided in the following descriptions are pseudonyms.

\section{Domain 1: Foundational Components of a Need-fulfilling Team Environment}

The first domain addressed components that emerged as foundational to a needfulfilling environment. These included: (a) groupness, (b) individual goals, (c) valued roles, and (d) mutual acceptance. Overall, these foundational components served to create a culture that nurtured the basic psychological needs of competence, autonomy, and relatedness.

Groupness. Participants described their squad as a cohesive unit striving toward one mutual purpose of continual improvement and excellence. While they competed individually in the water they felt like members of a team rather than independent athletes as Krystal described, "I don't even think about myself when I swim anymore, I think about how I can help the team." The feeling of togetherness as part of a unified group was something they had never experienced before in the sport of swimming. As Mary explained, this was possible because the team had multiple conversations "at the beginning of the season about what is means to be part of the team," which nurtured a sense of relatedness among athletes. Swimmers agreed that having these foundational discussions about the team's identity, rules, expectations, goals, and purpose was an important step to becoming a cohesive and successful group as Cody stated, "if you want to win a national championship there can't be stragglers you have to have everyone together. And we all have the same goal and I think we are all heading toward that same direction." The shared purpose and goal helped to develop a cohesive unit that swimmers described as physically and mentally close. Krystal called the team "a big [school color] blob and it never separates... our team is always physically close to each other" and "the team is one big unit and one big swimmer." Participants also experienced feelings such as pride, trust, and love that united them and contributed to their sense of belonging. For example, Elizabeth mentioned, "I know there are people that love me, support me, and want the best for me... swimming with all these people that share the same love for it, it's pretty special to have that common goal you're going after." The combination of a shared purpose and feelings of closeness made swimming fun and created an environment that nurtured participants' motivation to achieve and be part of the team. Harry stated that the swim team was a large group "having fun, working out, and achieving high standards of swimming" and "because we have such a close team... it is fun to swim." Thus, participants valued being part of a unified team rather than just an aggregate of individual athletes, which nurtured their perceptions of relatedness.

Individual Goals. Coaches cultivated an environment where participants internalized the importance of being knowledgeable about each other's individual goals. This process fostered a sense of accountability among the team and simultaneously enhanced athletes' individual perceptions of competence and relatedness. At the beginning of the season every swimmer created individual goals which 
were then openly discussed, visibly posted in the locker room, and consistently revisited and modified throughout the season. Not only did team members share their goals but they also conversed about what they were going to do to achieve them. This process nurtured a feeling of involvement and thus generated a sense of relatedness among the team, as Krystal pointed out, "you can be more engaged if you understand what [teammates] are trying to do, and I think that unifies the team quite a bit" and she went on to say, "when you know what other people want to do, and what their goals are and you are aware of them it's like you're more connected and more of a unit." Participants discussed that being knowledgeable about each other's goals allowed them to hold teammates accountable to stay on task, as Elizabeth stated, "we know each other's goals, pretty detailed goals and we remind each other of that... so if I see a teammate on the wall and she is not having a great practice... I remind her of her goal." This accountability not only created a sense of relatedness, but also nurtured a feeling of competence. Mary explained, "everyone on the team knows what the other people want to do, and they are really supportive of it so I think they make me feel very capable to achieve my goals." In sum, teammates demonstrated a genuine interest in each other's goals which created a sense of togetherness among the group and thus enhanced individuals' perceptions of relatedness. Furthermore, swimmers reminded their teammates about these goals in practice and made sure they stayed committed to achieving them. This culture of accountability helped athletes improve and consequently nurtured their need for competence.

Valued Roles. Participants discussed how swimmers had both formal and informal roles on the team that were valued and lead to the feeling that every person on the team matters. Specifically, formal and informal roles nurtured individuals' feelings of autonomy, competence, and relatedness. Formal leadership roles on a leadership committee, which were appointed by the coaching staff, were primarily held by seniors. Participants accepted that there was a sense of seniority and that upperclassmen had earned the right to be the primary decision makers about team matters. Furthermore, leaders' experience was valued, which generated a sense of autonomy for those participants. Harry, a sophomore, summarized this by stating, "I'm not as much of a leader as some of the older guys... I don't have the presence as someone who already has the experience and the wisdom of the older seniors on the team." Besides these formal roles a multitude of informal roles existed related to performance, encouragement, and support. These roles were not appointed but rather emerged naturally through teammates' interactions. William, who saw himself as a performer, described the variety of roles on the team in stating:

[Name] earned his because he wins races and he always, like he is just the toughest on the team. He always trains hard. And then there are other kids on the team who don't win races but they are, they have really good grades in school, and you know student-athlete. Student first, like we need just as much help from those guys, as they need from us.

Informal and formal roles matched swimmers' strengths and personalities which made individuals feel like valuable members of the team. For example, Susan described herself as: 
The motivator. I am definitely not the fastest girl that we have on the team by any means, but I feel like if somebody is having a bad day... I can usually talk to them and make them feel less anxious and less nervous and they can do better.

Having a variety of valued roles on the team which were not based solely on athletic performance allowed all swimmers to feel like capable members of the group. Therefore, individual roles primarily enhanced team members' perceptions of competence.

Acceptance. Participants described that a sense of acceptance among teammates enhanced their personal comfort and consequently nurtured their feelings of relatedness and autonomy. While established leaders were the primary decision makers, everyone was included in activities and conversations. For example, during team meetings swimmers felt like they were able to voice their opinion as Cody explained, "they [upperclassmen] are very accepting of your input" and "you can just throw in your input whenever." He further mentioned that as a freshman he had suggested a team value that was still in place. Thus, acceptance among members was demonstrated through acknowledging each other's input as meaningful contributions to the team, which nurtured swimmers' perceptions of autonomy. More importantly, this input was perceived as valued by others and at times even requested, which cultivated swimmers' perceptions of relatedness. For example, when asked about his ability to give his opinion Harry answered:

In fact, I feel like it's particularly frowned upon if you don't give your opinion, because it is considered so important that you give input and you are a part of the team, rather than just being an individual. So often, the people who don't actually participate or don't give their opinion are called upon and we are like 'Come on, what do you think?'

Team members did not try to directly change each other, which lead to swimmers feeling recognized and able to act naturally. Elizabeth mentioned that, "I have been myself and that's been accepted because I can see the way that they treat me, the way they show respect for me, the way I can see their love for me, their communication." Similarly, Mary explained, "there are just a lot of different personalities on the team and I haven't seen many people have to change who they are.' Some athletes on the team came from different countries with diverse cultural backgrounds; they were acknowledged and did not have to change their customs and behaviors to fit in. Overall, feeling accepted by other teammates created an environment that made it enjoyable for swimmers to be in and enhanced their perceptions of autonomy and relatedness.

\section{Domain 2: Elements in Practice that Nurtured Athletes' Perceptions of Competence}

The second domain addressed a variety of ways that teammate interactions in practice nurtured participants' perceptions of competence. These interactions included: (a) teammate recognition and support, (b) intrateam competition, and (c) peer coaching. It is worth noting that all three categories were also perceived to contribute to individual performance. 
Teammate Recognition and Support. Participants mentioned how meaningful the recognition and support of their teammates was. Specifically, praise and encouragement from other swimmers made individual athletes believe in their ability and consequently enhanced their perceptions of competence, as Mary stated, "no matter what [teammates] always make you feel like you can do better." Rachel further highlighted this by expressing, "hearing somebody saying, 'Come on you can do it. Keep up,' makes me put that little bit more into the effort... it creates a better or a faster time." This was particularly evident when feedback and support was perceived to be genuine and came from older and successful teammates as Harry mentioned, "if another good swimmer is saying, "well done that looks really good' or 'hey, you're swimming really quick,' just the acknowledgement of someone who is older or good at swimming... makes you feel more capable in yourself." Cody reinforced this and additionally discussed the power of others believing in his ability to exceed his personal expectations, "it makes you feel better that someone next to you sees more potential in you than what you... think you're capable of. So it's nice knowing that their vision for you exceeds what you thought you were capable of."

In addition, athletes participated in long and strenuous practices and all swimmers agreed that even the most motivated individuals have days when they struggle with fatigue and low perceived competence to complete the session. However, these hardships were endured together as a team, a concept that many participants had never experienced before in the sport of swimming. Cody supported this by explaining:

When you're just drained like at the end of practice... and then [teammates are] like 'come on you can do it... it's going to make you better.' And you're like 'yeah I can do it.' They're making you better and making themselves better and the team better just by pushing you. And you will turn to the guy next to you like 'come on you can do it...' you just pass it on and it's like a team value.

This support gave swimmers the confidence (i.e., enhanced their perceptions of competence) to complete difficult workouts as Krystal pointed out:

If I am personally struggling in practice and I feel like I am losing and falling off of the set, something like that [teammate's encouragement] will make me feel like 'no! I am good enough to do this and I am going to do this and I can do this.'

Therefore, teammates' recognition and support gave swimmers the motivation to endure challenging practices and satisfied their need for competence.

Intrateam Competition. "Good competition" among teammates was repeatedly discussed as a key element of the practice environment that contributed to increased confidence in the ability to perform and thus perceptions of competence among swimmers. Participants reported that coaches made a point of fostering opportunities to compete in every single practice by racing each other, having competition days, and posting individual times. As Mary stated, "there are just a lot of endless opportunities to compete. Usually in every practice there is something fast so you can get up and race the person next to you, so it's really competitive." As Harry discussed this was good and fun competition in which swimmers encouraged each other: 
The idea is that you are just willing to compete at your best, even if you are caught off guard, and so sometimes the coaches will just call [a race] at the start of practice at 5:30am... and you have to compete right there and then. And everybody just gets rowdy for it and gets behind each other's backs, so it's pretty fun.

Participants discussed that this competitiveness nurtured a culture where teammates pushed each other in practice and everyone had a strong desire to win. This was regarded as a positive way to improve each day and therefore fostered swimmers' perceptions of competence as Cody stated:

You can feel it, like you can taste it. It's crazy how much competition there is daily and it just brings the team together. It's good competition, it's not bad or negative, it's just making everyone better. It brings out the best in people... it brings out a lot of learning experiences that you can bring to dual meets or [conference championship] that can really help in the long run.

Elizabeth explained she used good competition to "pull confidence from for the next day, the next practice, and the next meet." Overall, intrateam competition brought out the best in each swimmer, helped to put forth maximum effort, made them want to get better, and enhanced their perception of competence, which assisted them to optimally prepare for swim meets.

Peer Coaching. Coaches created opportunities in practice where athletes observed each other and subsequently offered feedback. While this process was initialized by the coaches it was internalized by the swimmers as Mary stated:

It started from the coaching where they would put you in partners, but now it is just more natural. Like in the middle of practice and you see somebody doing something that could be done better or in an easier way and people have no problem calling it out.

When assuming the role of peer coach, swimmers corrected their teammates' technique and also highlighted what was done well. Team members discussed how providing and receiving feedback through peer coaching enhanced their perceptions of competence and maximized the effectiveness of each session. Rachel explained that, "sometimes you may think you are doing something well, but from an outside person looking on they may be able to tell you it is not quite right and they can tell you what to fix." According to Mary this system helped both parties benefit and learn in that, "it helps you improve because you have to verbalize what you know you're supposed to be doing and then you're also helping somebody else because you are fixing what they are doing wrong." This environment of ongoing learning and improvement satisfied athletes' need for competence as they became more confident in their abilities as swimmers.

In addition, peer coaching allowed participants to feel like contributors to the team and its success. For example, Cody stated that if a teammate "wins a national championship, then... you had something to do with it, you won that national championship with him. He's the one that has it, but you're the one that got him there." Thus, swimmers felt like they played a valuable role in the team's success which enhanced the feelings of togetherness and relatedness among athletes. In 
addition, peer coaching gave athletes an opportunity to work independently and without the explicit control of their coaches. Swimmers were able to provide input about teammates' performance and influence their own development. This fostered an autonomous practice climate in which athletes felt like they were able to make meaningful decisions. In sum, peer coaching helped athletes improve and enhanced their perceptions of competence while simultaneously offering them a sense of autonomy.

\section{Domain 3: Teammate Interactions Outside the Pool Which Impacted Athletes' Perceptions of Relatedness}

In the third domain, participants described that interacting with teammates outside of the athletic environment and adhering to social standards had an important impact on the team and nurtured perceptions of relatedness among swimmers. These interactions included: (a) social life, (b) conflicts, and (c) being on the same page.

Social Life. Swimmers discussed that while they were already around each other for long periods in practice, time outside the pool was mostly spent with team members as well. Some participants went as far as calling the team their entire social life, which nurtured individuals' perceptions of relatedness as they grew closer with teammates. Asked about how much time she spent with her teammates outside of the pool Elizabeth answered:

I live with swimmers and all my free time is with the swimmers. We only really associate with the swim team, which sounds crazy, but none of us have really wanted it any other way. We just do everything together and we are just a really big family.

To a certain extent, socializing with teammates was due to convenience, as Krystal stated, "I don't have time to meet other people" and participants often lived together on or off campus. However, this connection went deeper than a simple lack of opportunity to associate with nonswimmers. For example, Cody referred to his teammates as brothers, a sentiment shared by many male participants:

I mean they're your brothers and I mean it's kind of weird like you'd think you'd want to associate with other people outside of school or the pool because you'd probably get sick of them. But I've found that it's not like that you are closer with them outside because you can associate with them.

Thus, it was obvious that teammates played a significant role in participants' lives and there was a sense of togetherness enhancing individuals' perceptions of relatedness.

Conflicts. While interviews primarily focused on social interactions that satisfied swimmers' basic psychological needs, team members also mentioned conflicts that had the potential to negatively influence the need for relatedness. Participants reported that while certain minor disagreements happened in practice (e.g., how to structure warm-up), conflicts mainly occurred outside of the pool. Such issues were primarily related to having different interests, bickering, and intrateam dating. Many comments related to minor conflicts were directed at problems between 
female and male swimmers, as Harry said "you kind of get clashes because of gender differences. Often a group of guys will think something is funny and a group of girls won't." It is important to note that participants reported that such minor conflicts typically did not negatively influence the team as a unit or thwart their perceptions of relatedness. It was problems related to going against the team purpose and identity that participants took more seriously. Mary mentioned that team members had a responsibility as she stated, "I know I represent myself, my family, but then also I have got this whole team I represent." It was particularly partying and breaking rules that at times led to a divide among the team and decreased a sense of togetherness. Elizabeth was troubled by such events "when they go off and break rules or... [go] out on a weekend that they weren't supposed to... I kinda take it personally because it makes me feel like the team is not really important to them." While team members played a significant role in swimmers' lives these relationships also created potential issues that challenged feelings of togetherness and thus perceptions of relatedness.

Being on the Same Page. When conflicts arose that could have had negative effects on swimmers' need fulfillment, they were generally resolved within the group through positive communication in individual discussions or team meetings. Harry explained that there was a system in place in which:

You have to talk it out with the person first. So let's say I have a problem I just go up to them, bring it up, and talk about it, and if they are like 'Sorry, I didn't realize I was doing this. I didn't mean to offend you,' you can just both put it behind you and move on. If that's not the case and you both disagree then obviously you can talk to the team captains, seniors, or your other friends on the team and get their input. If it still gets even worse you can talk to the coaches, but I feel like the team tries to keep it within the team.

Participants valued "being on the same page" and therefore conflicts were directly addressed and solved in meetings before they decreased swimmers' perceptions of relatedness. In those meetings the team made a point of holding every member to a standard that was in accordance to the group's values and goals as Elizabeth shared:

When we sit down at the beginning of the year and think about what we want to be... holding each other accountable, so when someone messes up you know by going out when they shouldn't have, they are punished, and they have to talk to us as a team and we all talk it out, it's just accountability and following through it, not just putting out a goal or rule throughout the season, we really talk about it.

This accountability nurtured a mutual respect and value for each other as Krystal pointed out, "everyone has their own way of doing things and as long as you trust peoples' intentions, like they really want to be here for the team... every team has conflicts, but I think we are a pretty strong team." This respect further allowed a large team with individuals who have varying personalities to be on the same page and move in a common direction. Participants discussed the importance of adhering to the team values and Mary mentioned always trying to behave accordingly to "project the team values, so that you don't do anything that will negatively affect 
it." Therefore, swimmers were able to create an environment in which conflicts were resolved quickly and members' perceptions of relatedness nurtured.

\section{Discussion}

The primary aim of this qualitative study was to gain an in-depth understanding of the ways in which teammate interactions — among a NCAA DI swim team-satisfied participants' perceptions of competence, autonomy, and relatedness. Overall, a majority of the need-fulfilling teammate interactions swimmers identified represented values, goals, and behaviors that were first initiated and reinforced by the coaches. However, through the interviews, it became evident that participants internalized or "bought-in" to these socially sanctioned mores and actively accepted them as their own. For example, developing a sense of groupness, being knowledgeable about teammates' goals, supporting each other, engaging in constructive intrateam competition, and coaching peers during practice became personally endorsed.

The internalization process has been measured in previous research by assessing the degree of need fulfillment (e.g., Hollembeak \& Amorose, 2005). While the current study did not quantitatively measure the degree of basic psychological need satisfaction or motivation, participants clearly discussed the role of teammate interactions in enhancing their perceptions of competence, autonomy, and relatedness. Subsequently, this need fulfillment helped swimmers learn and enact their team's values, goals, and behaviors. For example, participants initially did not engage in behaviors such as goal setting or peer coaching on their own, but they learned and enacted them because of the social mores associated with practice. Accordingly, it appears possible that behaviors, which may have initially been engaged in for non-self-determined reasons (i.e., external and introjected regulation) were internalized by swimmers through need-satisfying teammate interactions. Therefore, while coaches are often considered the main influence on athletes' sport participation (Mageau \& Vallerand, 2003) and have been the primary target of research within self-determination theory (e.g., Hollembeak \& Amorose, 2005) the current study highlights the valuable role of teammates. Coaches should consider ways to nurture need-fulfilling interactions among their team as they might then merely need to set the appropriate foundation for expected values, goals, and behaviors. When these are successively encouraged and enforced through members of the team, individuals are more likely to "identify with the importance of social regulations, assimilate them into their integrated sense of self-and thus fully accept them as their own" (Deci \& Ryan, 2000, p. 236) and consequently foster more harmonious team environments. Deci and Ryan (2000) argued that:

Cultures (and cultural subgroups such as families, clubs, and work groups) provide tools, practices, and values that can allow people to satisfy basic needs, to feel volition and choice as well as cohesion and relatedness. Insofar as this occurs, we would expect to find human health and well-being. However, if the values and goals are not well integrated, for example because the cultural or subcultural context is chaotic and pressuring rather than optimally challenging and supportive, we would expect to find not only constituents who evidence less well-being but cultures themselves that are less stable and more fragmented (p. 247). 
In sum, the swimmers' experiences in this study reinforced Deci and Ryan's (2000) contentions.

Therefore, the remainder of the discussion is focused on the types of teammate interactions found in the current study that cultivated a need-fulfilling environment and likely enhanced the process of internalization. While most research investigating internalization has been quantitative in nature the current study offered insight into the ways (i.e., how) teammates and coaches can help athletes internalize values, goals, and behaviors within the sport context.

\section{Developing a Sense of Groupness}

At the beginning of the season, swimmers had foundational discussions about the team's identity, rules, expectations, goals, and established a purpose that emphasized continual improvement and excellence. Throughout the season these foundational elements were revisited and reinforced during practices and in team meetings, which was critical to remaining on the same page. This process appeared to be the first step in developing a need-fulfilling environment and nurtured interactions where teammates internalized the importance of working together as a cohesive unit. Evans and colleagues (2013) found that groupness (i.e., the degree to which athletes share a common fate rather than solely being an aggregate of individuals) varies among individual sport teams (e.g., swimming) because members are in a position to choose the degree to which they work together. In the current study, it was clear that the internalization process, which was fostered through need-fulfilling teammate interactions, shaped participants' perceptions of the importance of a high degree of groupness. Swimmers had created a team environment in which they helped each other to strive toward continual improvement and excellence, which nurtured their perceptions of competence. In addition, participants described their team with words such as pride, trust, love, and physical closeness, which fostered their perception of relatedness. While researchers have primarily focused on the contribution of one quality friendship on a team in enhancing an individual's perception of relatedness (e.g., Kipp \& Weiss, 2013), this study emphasizes the power of positive interactions among the team as a whole in creating one cohesive unit striving toward one purpose. In sum, teammate interactions that cultivated groupness simultaneously nurtured basic psychological need satisfaction.

\section{Being Knowledgeable About Teammates' Goals}

Goal setting was a practice that nurtured a sense of involvement and accountability among teammates. In particular, making the effort to know each other's goals allowed team members to interact in ways that generated a sense of togetherness (i.e., relatedness) and helped them stay confident and focused on the task (i.e., competence). While individual goal setting has previously been found to enhance feelings of competence (Lamont \& Kennelly, 2012), the current results highlights the benefits of peer involvement which can foster accountability. Furthermore, although Joesaar and colleagues (2011) did not assess the role of goal setting, they did find that when teammates helped each other learn and improve, these interactions also enhanced feelings of competence, autonomy, and relatedness. The present research supports these findings by showing that engaging in individual goal 
setting procedures as a group helped teammates work together and simultaneously nurtured basic psychological need satisfaction.

\section{Supporting Each Other}

The results of the present research highlight teammate recognition and support as another value that can foster perceptions of competence. Social support is considered a multidimensional construct that can provide emotional (i.e., comfort and caring), esteem (i.e., encouragement and praise), tangible (i.e., instrumental and practical assistance), network (i.e., integration in a group of similar others), and informational (i.e., advice, suggestions, and guidance) assistance to athletes (see Hassell, Sabiston, \& Bloom, 2010). In the current study, the types of social support participants discussed seemed to align with all of these except tangible support. Previous research regarding peers as providers of social support has been limited, yet Hassell et al. (2010) found similar results in a qualitative study with nine elite female swimmers between the ages of 13 and 15 . The primary difference to the present results was that Hassell et al. (2010) concluded that peers only provided limited if any informational support and called for more research to explore contextual factors that determine sport-related information exchange between teammates. The current findings suggest that such support may be more likely on collegiate teams that have athletes with potentially more sport-specific knowledge to share. The present study further proposes that teammates' support fostered swimmers' perception of competence. In sum, the current results support Hollembeak and Amorose's (2005) call for research within self-determination theory to examine how the different types of social support may or may not be associated with perceptions of competence, autonomy, and relatedness.

\section{Engaging in Constructive Intrateam Competition}

Athletes acknowledged the importance of constructive intrateam competition in fostering motivation in practice and thus allowing for more successful performances. Participants further reported that racing with highly talented swimmers in practice enhanced their perception of competence and optimally prepared them for swim meets. This belief is in line with the games-approach to skill practice (see Wrisberg, 2007), which supports the idea that athletes benefit from training in practice environments that easily transfer and mirror the demands of competition. The primary advantage is that swimmers, for example, will be ready to perform in meets as they have prepared for the circumstances and added demands every day at practice.

Vallerand and Losier (1999) indicated that competition generally decreases individuals' self-determined motivation. Specifically, when a sport context emphasizes beating an opponent or winning a prize, athletes' perceptions of autonomy are undermined. In addition, losing a competition can lower athletes' perceptions of competence. According to Vallerand and Losier (1999), this is particularly evident in highly competitive settings such as collegiate athletics. In contrast, the current findings suggest that cooperation (which has been shown to enhance selfdetermined motivation; Vallerand \& Losier, 1999) and competition are compatible when there is a partnership, a mutual striving for excellence, and when it is viewed as a shared quest to improve. "Thus, the key element in competitive events may be to encourage participants to focus on the mastery dimensions of the activity and 
not on the extrinsic (winning) dimensions" (Vallerand \& Losier, 1999, p. 149). In the current study, need-fulfilling teammate interactions appeared to nurture such a mastery-oriented climate (i.e., focused on doing as best as one can) and consequently enhanced participants' perceptions of the value of competing against their peers. However, more research appears warranted to explore the personal and social factors that influence the effect of intrateam competition on basic psychological need satisfaction.

\section{Coaching Peers During Practice}

Peer coaching and correcting each other's technique in practice helped swimmers improve individually and also become more connected with other team members. Participants mentioned that this allowed them to feel like everyone played a valuable role in the team's success, empowered athletes, allowed for independent work, and set a standard for excellence and positive encouragement, thus enhancing perceptions of competence, autonomy, and relatedness. These outcomes are in line with suggestions by Mageau and Vallerand (2003) who argued that coaches can foster athletes' basic psychological need satisfaction by allowing them to take ownership of their team through independent work and involvement; peer coaching seems to accomplish both. Allen, McManus, and Russell (1999) previously reported the benefits of peer mentoring for graduate students, who experienced enhanced socialization of newcomers, lower levels of stress, and better work performance as a result of this practice. The current findings suggest that peer mentoring or more specifically coaching can lead to similar positive outcomes and nurtures need fulfillment in the sport context.

\section{Potential for Conflict}

Teammate interactions in the current study were predominantly positive. Yet, there was also the potential for conflicts, which could negatively influence need fulfillment. It appears noteworthy that most of these conflicts appeared to occur outside of the sport environment where coaches have much more limited control to emphasize important values, goals, and behaviors that are then internalized by the team. Thus, it would be valuable to explore such norms beyond the sport context to facilitate the multitude of roles student-athletes play. Participants in the current study spend their free time almost exclusively with teammates, which developed even stronger relationships among the group but also often left teammates as the sole social factor for swimmers' basic psychological need satisfaction. While beyond the scope of this study, it should therefore be noted that collegiate swimmers almost exclusively spending time with teammates might not necessarily be an adaptive behavior. Hassell et al. (2010) previously suggested that elite youth athletes often struggle with social relationships outside their sport context as others cannot identify with their training, commitment, and competition. However, the present findings emphasized the value of having athletes who foster their perception of competence, autonomy, and relatedness utilizing multiple feedback channels and social factors. Finally, while it seemed that negative interactions resulted in need thwarting, which should be considered conceptually different from low need satisfaction (Costa et al., 2015), this distinction was outside the purpose of the current study and should be explored further in future research. 


\section{Practical Strategies}

While it was ultimately teammates who influenced each other the present findings also highlight the importance of coaches as they implemented strategies and created an atmosphere that helped athletes internalize team values, goals, and behaviors. Thus, coaches appear to have both a direct and indirect impact on athletes' basic psychological need satisfaction. The current results offer strategies that can be used by sport psychology professionals and coaches to foster basic psychological need satisfaction and cultivate effective team environments.

It appeared that nurturing groupness among the team created the foundation for positive peer interactions. Thus, athletes should be encouraged to establish their team's identity, rules, expectations, goals, and purpose early in the season and consistently revisit them. This can be achieved through team meetings that can also be valuable in resolving conflict should it arise. In addition, establishing formal and informal roles makes individuals feel like valuable members of the group. In practice it is beneficial to create opportunities for "good competition," which allows swimmers to optimally prepare for racing. This can be achieved by incorporating competitive elements (such as races) into practice or acknowledging individual times, especially as compared with an athlete's own goals. Furthermore, having training partners and integrating peer coaching empowers athletes by avoiding explicit control from coaches. Finally, goal setting is a strategy that helps athletes strive toward success. Both individual as well as team goals should be established before the season, posted visibly in the locker room or other team facilities and revisited throughout the year to foster a sense of accountability. These recommendations are not inherently new, but what can be appreciated is how they contribute both to improved performance as well as the basic psychological need satisfaction of student-athletes.

Overall, creating a need-fulfilling team environment seems to be more effective when coaches and athletes work together. Thus, potential similarities and differences between the influences of these two social factors (i.e., coaches and teammates) on need fulfillment should be explored further in future research. In addition, the current study highlight that satisfaction of all three basic psychological needs is important to nurture the internalization process. While the elite athletic context might often emphasize competence due to its focus on results (Frøyen \& Pensgaard, 2014) the need for relatedness, which has previously been labeled as distal (Deci \& Ryan, 2000), played a meaningful role in swimmers' experience and enhanced their internalization of values, goals, and behaviors.

\section{Limitations}

While this investigation was able to offer valuable theoretical and practical findings, there were some limitations that should be addressed in future research. Conclusions provided an understanding of the psychological constructs under examination; however, results were based on athletes from one team and could therefore have been specifically related to the participating team and its members. While the findings that emerged were primarily positive, gaining more information on how teammates thwart basic psychological need satisfaction can add another perspective and offers a more comprehensive exploration of psychological experiences (Costa et al., 2015). High levels of success have the potential to foster basic psychological 
need satisfaction, which would then be difficult to separate from teammates' influence. In contrast, failure might create contextual conditions where peers are not as supportive of each other's needs. Therefore, it is important to understand social influences on need fulfillment among teams that objectively experience success and/or failure. In this context, the participating team was nationally ranked (both women and men) at the time of the study. Hence, having athletes from different teams with contrasting group structures and multiple sports can complement the range of findings. Finally, the study did not include an exploration of actual behavioral regulation which would have added to the comprehensiveness of the results and could have offered further evidence for the proposed internalization of goals, values, and behaviors.

\section{Conclusion}

Overall, the study used a qualitative framework which has received limited attention within the self-determination theory literature. Thus, the current findings offer an intriguing compliment to previous quantitative work. Based on these results, it might be concluded that teammates had a meaningful influence on NCAA DI swimmers' basic psychological need satisfaction of competence, autonomy, and relatedness. In turn, this need fulfillment helped them learn and enact their team's values, goals, and behaviors. Thus, it appears that behaviors such as goal setting or peer coaching were internalized by participants through need-satisfying teammate interactions. This need fulfillment, especially the enhancement of internalization, seems valuable given the direct influence on self-determined motivation and psychological well-being (Deci \& Ryan, 2000). The research further provides an initial understanding for how such interactions can be nurtured. In addition, the impact of peer interactions on perceived need fulfillment was evident across different contexts, indicating a reciprocal effect between basic psychological need satisfaction in and out of sport (see Vallerand, 1997). Teammates not only affected participants' perceptions of competence, autonomy, and relatedness in the context of sport, but also in their social life. This balance in need satisfaction (i.e., fulfillment in and out of sport) has been shown to enhance adjustment (Milyavskaya et al., 2009) and prevent athlete burnout (i.e., long-term exhaustion and diminished interest; Perreault, Gaudreau, Lapointe, \& Lacroix, 2007), two of many important outcomes that coaches and teammates can influence for athletes in the competitive sport environment. In sum, peers appear to play a valuable role in determining an individual's collegiate sport experience and therefore teammate interactions should receive meaningful consideration when developing team environments such that they can optimize student-athlete well-being and performance.

\section{References}

Allen, T.D., McManus, S.E., \& Russell, J.E.A. (1999). Newcomer socialization and stress: Formal peer relationships as a source of support. Journal of Vocational Behavior, 54, 453-470. doi:10.1006/jvbe.1998.1674

Carron, A.V., Colman, M.M., Wheeler, J., \& Stevens, D. (2002). Cohesion and performance in sport: A meta-analysis. Journal of Sport \& Exercise Psychology, 24, 168-188. 
Costa, S., Ntoumanis, N., \& Bartholomew, K.J. (2015). Predicting the brighter and darker sides of interpersonal relationships: Does psychological need thwarting matter? Motivation and Emotion, 39, 11-24. doi:10.1007/s11031-014-9427-0

Cox, A., Duncheon, N., \& McDavid, L. (2009). Peers and teachers as sources of relatedness perceptions, motivation, and affective responses in physical education. Research Quarterly for Exercise and Sport, 80, 765-777. PubMed doi:10.1080/02701367.200 9.10599618

Deci, E.L., \& Ryan, R.M. (2000). The "what" and "why" of goal pursuits: Human needs and the self-determination of behavior. Psychological Inquiry, 11, 227-268. doi:10.1207/ S15327965PLI1104_01

DeFreese, J.D., \& Smith, A.L. (2013). Teammate social support, burnout, and self-determined motivation in collegiate athletes. Psychology of Sport and Exercise, 14, 258-265. doi:10.1016/j.psychsport.2012.10.009

Evans, B., Eys, M., \& Wolf, S. (2013). Exploring the nature of interpersonal influence in elite individual sport teams. Journal of Applied Sport Psychology, 25, 448-462. doi:1 0.1080/10413200.2012.752769

Frøyen, A.F., \& Pensgaard, A.M. (2014). Antecedents of need fulfillment among elite athletes and coaches: A qualitative approach. International Journal of Applied Sports Sciences, 26, 26-41.

Gillet, N., Berjot, S., \& Gobance, L. (2009). A motivational model of performance in the sport domain. European Journal of Sport Science, 9, 151-158. doi:10.1080/17461390902736793

Gould, D., Dieffenbach, K., \& Moffett, A. (2002). Psychological talent and their development in Olympic champions. Journal of Applied Sport Psychology, 14, 172-204. doi:10.1080/10413200290103482

Hanson, D.M., Larson, R.W., \& Dworkin, J.B. (2003). What adolescents learn in organized youth activities: A survey of self-reported development experiences. Journal of Research on Adolescence, 13, 25-55. doi:10.1111/1532-7795.1301006

Hassell, K., Sabiston, C.M., \& Bloom, G.A. (2010). Exploring the multiple dimensions of social support among elite female adolescent swimmers. International Journal of Sport Psychology, 41, 340-359.

Hill, C.E., Thompson, B.J., \& Williams, E.N. (1997). A guide to conducting consensual qualitative research. The Counseling Psychologist, 25, 517-572. doi:10.1177/0011000097254001

Hill, C.E., Thompson, B.J., Hess, S.A., Knox, S., Williams, E.N., \& Ladany, N. (2005). Consensual qualitative research: An update. Journal of Counseling Psychology, 52, 196-205. doi:10.1037/0022-0167.52.2.196

Hollembeak, J., \& Amorose, A.J. (2005). Perceived coaching behaviors and college athletes' intrinsic motivation: A test of self-determination theory. Journal of Applied Sport Psychology, 17, 20-36. doi:10.1080/10413200590907540

Horn, T.S. (2011). Multiple pathways to knowledge generation: Qualitative and quantitative research approaches in sport and exercise psychology. Qualitative Research in Sport, Exercise and Health, 3, 291-304. doi:10.1080/2159676X.2011.607181

Joesaar, H., Hein, V., \& Hagger, M.S. (2011). Peer influence on young athletes' need satisfaction, intrinsic motivation and persistence in sport: A 12-month prospective study. Psychology of Sport and Exercise, 12, 500-508. doi:10.1016/j.psychsport.2011.04.005

King, S. (2014). Athlete and coach perceptions of basic psychological needs fulfillment: A qualitative exploration of self-determination theory constructs in collegiate swimming (Unpublished Master's Thesis). University of Wyoming, Laramie, WY.

Kipp, L.E., \& Weiss, M.R. (2013). Social influences, psychological need satisfaction, and well-being among female adolescent gymnasts. Sport, Exercise, and Performance Psychology, 2, 62-75. doi:10.1037/a0030236 
Lamont, M., \& Kennelly, M. (2012). A qualitative exploration of participant motives among committed amateur triathletes. Leisure Sciences: An Interdisciplinary Journal, 34, 236-255. doi:10.1080/01490400.2012.669685

Mack, D.E., Wilson, P.M., Oster, K.G., Kowalski, K.C., Crocker, P.R.E., \& Sylvester, B.D. (2011). Well-being in volleyball players: Examining the contributions of independent and balanced psychological need satisfaction. Psychology of Sport and Exercise, 12, 533-539. doi:10.1016/j.psychsport.2011.05.006

Mageau, G.A., \& Vallerand, R.J. (2003). The coach-athlete relationship: A motivational model. Journal of Sports Sciences, 21, 883-904. PubMed doi:10.1080/0264041031000140374

Merriam, S.B. (2009). Qualitative research - A guide to design and implementation. San Francisco, CA: Jossey-Bass.

Milyavskaya, M., Gingras, I., Mageau, M., Koestner, R., Gagnon, H., Fang, J., \& Boiche, J. (2009). Balance across contexts: Importance of balanced needs satisfaction across various life domains. Personality and Social Psychology Bulletin, 35, 1031-1045. PubMed doi:10.1177/0146167209337036

Perreault, S., Gaudreau, P., Lapointe, M-C., \& Lacroix, C. (2007). Does it take three to tango? Psychological need satisfaction and athlete burnout. International Journal of Sport Psychology, 38, 437-450.

Pierce, R.G., Sarason, I.G., \& Sarason, B.R. (1996). Coping and social support. In M. Zeidner \& N.S. Endler (Eds.), Handbook of Coping (pp. 434-451). New York, NY: Wiley.

Podlog, L., \& Dionigi, R. (2010). Coach strategies for addressing psychological challenges during the return to sport from injury. Journal of Sports Sciences, 28, 1-12. PubMed doi: $10.1080 / 02640414.2010 .487873$

Raabe, J. (2013). Self-determination theory in the context of collegiate cheer: An explorative study (Unpublished Master's Thesis). University of Wyoming, Laramie, WY.

Seidman, I. (2006). Interviewing as qualitative research. New York, NY: Teachers College Press.

Steinfeldt, J.A., Zakrajsek, R.A., Bodey, K.J., Middendorf, K.G., \& Martin, S.B. (2013). Role of uniforms in the body image of female college volleyball players. The Counseling Psychologist, 41, 791-819. doi:10.1177/0011000012457218

Teixeira, P.J., Carraca, E.V., Markland, D., Silva, M.N., \& Ryan, R.M. (2012). Exercise, physical activity, and self-determination theory: A systematic review. The International Journal of Behavioral Nutrition and Physical Activity, 9, 78-107. PubMed doi:10.1186/1479-5868-9-78

Vallerand, R.J. (1997). Toward a hierarchical model of intrinsic and extrinsic motivation. In M.P. Zanna (Ed.), Advances in experimental social psychology (pp. 271-360). New York, NY: Academic Press. doi:10.1016/S0065-2601(08)60019-2

Vallerand, R.J., \& Losier, G.F. (1999). An integrative analysis of intrinsic and extrinsic motivation in sport. Journal of Applied Sport Psychology, 11, 142-169. doi:10.1080/10413209908402956

Watt, S.K., \& Moore, J.L. (2001). Who are student athletes? New Directions for Student Services, 93, 7-18. doi:10.1002/ss.1

Wrisberg, C.A. (2007). Sport skill instruction for coaches. Champaign, IL: Human Kinetics. 